\title{
Synthesis, Crystal Structure, Electric and Magnetic Properties of $\mathrm{LaVO}_{2.78} \mathbf{N}_{\mathbf{0 . 1 0}}$
}

\author{
Songhak Yoon, ${ }^{[a]}$ Alexandra E. Maegli, ${ }^{[a]}$ Lassi Karvonen, ${ }^{[a]}$ Andrey Shkabko, ${ }^{[a]}$ \\ Sascha Populoh, ${ }^{[a]}$ Krzysztof Gałazka, ${ }^{[a, b]}$ Leyre Sagarna, ${ }^{[a]}$ Myriam H. Aguirre, ${ }^{[a]}$ \\ Peter Jakes, ${ }^{[\mathrm{cc}]}$ Rüdiger A. Eichel, ${ }^{[\mathrm{c}]}$ Stefan G. Ebbinghaus, ${ }^{[\mathrm{d}]}$ Simone Pokrant, ${ }^{[\mathrm{a}]}$ and \\ Anke Weidenkaff*[a,e]
}

\author{
Dedicated to Professor Reinhard Nesper on the Occasion of His 65th Birthday
}

Keywords: Lanthanum vanadium oxynitride; Electrical conductivity; Thermoelectricity; Perovskites; Oxynitrides

\begin{abstract}
Perovskite-type $\mathrm{LaVO}_{2.78} \mathrm{~N}_{0.10}$ powder was synthesized by thermal ammonolysis of the oxide precursor $\mathrm{LaVO}_{4}$. By X-ray, neutron, and electron diffraction an orthorhombic crystal structure with space group Pnma was identified. XANES spectra showed that the oxidation state of vanadium changes from $5+$ in $\mathrm{LaVO}_{4}$ to approximately $3+$ in $\mathrm{LaVO}_{2.78} \mathrm{~N}_{0.10}$. The temperature dependence of the electrical conductivity revealed an Arrhenius-type behavior with an activation energy of $0.103 \mathrm{eV}$ in the temperature range of $119-302 \mathrm{~K}$ indi-
\end{abstract}

cating that the conduction process is thermally activated band transition. Based on the positive Seebeck coefficient, holes were identified as the dominant charge carriers in the temperature range of 100-302 K. Both the Seebeck coefficient and the thermal conductivity showed an anomaly at $138 \mathrm{~K}$, which is attributed to the Néel temperature for antiferromagnetic ordering according to magnetic susceptibility measurements.

\section{Introduction}

Since the first investigations of the perovskite crystal structure by X-ray diffraction in the 1940 's, ${ }^{[1]}$ perovskite-type oxides have been the most widely studied materials among all ternary oxides. Perovskites have attracted much research interest due to their substantial physical and chemical properties including high- $\mathrm{T}_{\mathrm{c}}$ superconductivity, ${ }^{[2]}$ colossal magnetoresistance (CMR), ${ }^{[3]}$ dielectric, ferroelectric, piezoelectric, and multiferroic properties, ${ }^{[4]}$ thermoelectricity, ${ }^{[5]}$ nonlinear optical

* Prof. Dr. A. Weidenkaff
Fax: +41-58-765-4019
E-Mail: weidenkaff@imw.uni-stuttgart.de

[a] Laboratory for Solid State Chemistry and Catalysis

Empa - Swiss Federal Laboratories for Materials Science and Technology

Überlandstrasse 129

8600 Dübendorf, Switzerland

[b] Department of Chemistry and Biochemistry

University of Berne

Freiestrasse 3

3012 Berne, Switzerland

[c] Institut für Energie und Klimaforschung IEK-9

Forschungszentrum Jülich

Wilhelm-Johnen-Straße

52428 Jülich, Germany

[d] Institut für Chemie

Martin-Luther Universität Halle-Wittenberg

Kurt-Mothes-Straße 2

06120 Halle/Saale, Germany

[e] Institute for Materials Science

University of Stuttgart

Heisenbergstr. 3

70569 Stuttgart, Germany properties $^{[6]}$ and photocatalytic activity. ${ }^{[7]}$ The general chemical formula of perovskite-type oxides is $\mathrm{ABO}_{3}$, where $\mathrm{A}$ and $\mathrm{B}$ are different-sized cations with $A$ typically being alkali, alkaline earth, or rare earth cations, and $B$ transition metal cations. Due to its structural and compositional flexibilities, the perovskite structure is sustained even with extensive substitutions aimed at modulating the electronic structure, charge carrier concentration and thus fine-tuning of physical and chemical properties. $^{[8]}$

So far cationic substitution has been the most common way to tailor perovskite-type materials. Partial anionic substitution of nitrogen for oxygen offers an alternative to cationic substitution, producing a number of interesting physical properties for technical applications. ${ }^{[9]}$ By partially replacing oxygen with nitrogen the valence band is formed of a mixture of oxygen and nitrogen $2 p$ orbitals resulting in narrowing the energy bandgap. Thus, proper control of the nitrogen content enables modulation of the energy bandgap, which is the decisive factor determining the optical, electrical, and photocatalytic properties. Perovskite-type oxynitrides with the formula $A B \mathrm{O}_{3-x} \mathrm{~N}_{x}$ exhibit a wide spectrum of interesting physical and chemical properties. For example, Kim et al. reported high dielectric constants of $\mathrm{BaTaO}_{2} \mathrm{~N}$ and $\mathrm{SrTaO}_{2} \mathrm{~N}$ of about 4900 and 2900 at room temperature, respectively. ${ }^{[10]} \mathrm{LaTiO}_{2} \mathrm{~N}^{[7]}$ and $\mathrm{SrNbO}_{2} \mathrm{~N}^{[11]}$ show promising photocatalytic and photoelectrochemical properties for water splitting under visible light irradiation. By incorporating magnetic rare earths such as $\mathrm{Eu}^{2+}$ in the perovskite lattice, remarkable electronic flexibility and 
colossal magnetoresistance have been discovered in $\mathrm{EuNbO}_{2} \mathrm{~N}$ and EuWON ${ }_{2} \cdot{ }^{[12]}$ The electrical conductivity of $\mathrm{SrMoO}_{2.6} \mathrm{~N}_{0.4}$ and $\mathrm{SrMoO}_{2} \mathrm{~N}$ have been investigated. ${ }^{[13]}$ Lie et al. reported that metallic behavior for $\mathrm{SrMoO}_{2.6} \mathrm{~N}_{0.4}$ in the temperature range of 5-290 $\mathrm{K}^{[13 \mathrm{a}]}$ and Logvinovich et al. presented that semiconductor-like electrical resistivity for $\mathrm{SrMoO}_{2} \mathrm{~N}$ in the temperature range of $3-300 \mathrm{~K} \cdot{ }^{[13 \mathrm{c}]} \mathrm{LaWO}_{x} \mathrm{~N}_{3-x}(0.6<x<$ 0.8 ) also showed semiconducting electrical transport properties. ${ }^{[14]}$ However, comparatively few studies have been carried out concerning the synthesis, crystal structure, electric, and magnetic properties of perovskite-type vanadium oxynitrides. ${ }^{[15]}$ Possible short- and long-range ordering in the crystal structures and thermal stability are not fully described, and the mechanism of the electrical transport is not well understood yet. In this study, we report the synthesis for a lanthanum vanadium oxynitride sample with the composition of $\mathrm{LaVO}_{2.78} \mathrm{~N}_{0.10}$. The changes in long- and short-range order of the crystal structure were thoroughly investigated by powder $\mathrm{X}$-ray diffraction (XRD), powder neutron diffraction (ND), electron diffraction (ED), and X-ray absorption near edge structure (XANES) spectroscopy. Furthermore, electrical and magnetic properties are described in detail.

\section{Results and Discussion}

The anionic composition of the synthesized oxynitride was determined by hot-gas extraction and the obtained stoichiometric composition was $\mathrm{LaVO}_{2.78(2)} \mathrm{N}_{0.10(2)}$ (in the following the sample is referred to as $\mathrm{LaVO}_{2.78} \mathrm{~N}_{0.10}$ ). At temperatures higher than $600{ }^{\circ} \mathrm{C}$ ammonia undergoes significant decomposition ${ }^{[16]}$ and partial decomposition of $\mathrm{NH}_{3}$ is also reported to produce active nitriding species $\left(\mathrm{NH}, \mathrm{NH}_{2}\right)$ along with molecular hydrogen. ${ }^{[17]}$ The formed hydrogen can reduce the precursor $\mathrm{LaVO}_{4}$ to $\mathrm{LaVO}_{3-x}$ and the active nitriding species reacts with the reduced lanthanum vanadium oxide resulting in $\mathrm{LaVO}_{3-x} \mathrm{~N}_{y}$. Thus $\mathrm{NH}_{3}$ can act as a reducing and a nitriding agent during thermal ammonolysis inducing oxygen deficiencies in the perovskite structure. Reportedly nitridation kinetics are such that the nitrogen content still increases even after several days of thermal ammonolysis. ${ }^{[15]}$ However, as the ammonolysis conditions including temperature, interaction time, and $\mathrm{NH}_{3}$ flow rate are not precisely given in the literature, ${ }^{[15]}$ the nitrogen content in this study cannot be directly compared to the reported data. In our work, $\mathrm{NH}_{3}$ mainly provides a reducing atmosphere and only partly a nitriding agent and consequently, a nitrogen-poor oxynitride was obtained. With a prolonged ammonolysis of $19 \mathrm{~h}$ at $1123 \mathrm{~K}$ under flowing $\mathrm{NH}_{3}$ $\left(100 \mathrm{~mL} \cdot \mathrm{min}^{-1}\right)$, a secondary phase $\mathrm{La}_{2} \mathrm{O}_{3-x} \mathrm{~N}_{y}$ was detected by XRD (data not shown). Therefore, long ammonolysis times that might be beneficial for an enhanced incorporation of nitrogen also give rise to secondary phases.

Figure 1(a) shows the XRD pattern and Le Bail fit of $\mathrm{LaVO}_{2.78} \mathrm{~N}_{0.10}$. All peaks were indexed to the perovskite-type orthorhombic crystal structure (space group Pnma) and details of the structure refinement are listed in Table 1. As the X-ray atomic scattering factors of oxygen and nitrogen are nearly identical, the two elements cannot be distinguished by XRD.
Furthermore, XRD patterns of perovskite-type oxynitrides are usually dominated by the contribution of the heavier cations making it difficult to obtain detailed and correct structural information (i.e. the atomic positions, atomic displacement parameters (ADPs), and site-occupation factors) of the anions. ${ }^{[18]}$ Therefore, ND is the method of choice for the determination of the crystal structure of perovskite oxynitrides. Figure 1(b) shows the powder ND pattern and Rietveld refinement profile of $\mathrm{LaVO}_{2.78} \mathrm{~N}_{0.10}$. The refined structural parameters and agreement factors from the ND data are summarized in Table 1. The structural parameters of orthorhombic $\mathrm{LaVO}_{2.78} \mathrm{~N}_{0.10}$ are listed in Table 2. From the refined site-occupancy factors, mole fractions of oxygen and nitrogen of 2.88 and 0.10 , respectively, were calculated. Together with the presence of anion vacancies, the amount of nitrogen is small. The refined nitrogen/ oxygen occupancies are therefore less accurate, as it is shown by the observed differences between refined oxygen content 2.88 and analyzed oxygen content 2.78. Lattice parameters and unit-cell volume of $\mathrm{LaVO}_{2.78} \mathrm{~N}_{0.10}$ are larger than those of $\mathrm{LaVO}_{3}$ presented in previous papers. ${ }^{[19]}$

Furthermore, $\mathrm{LaVO}_{2.78} \mathrm{~N}_{0.10}$ crystallites were studied by HR-TEM and SAED in order to gain a deeper insight into the local microstructure. A representative HR-TEM image is given in Figure 2(a). It shows lattice fringes oriented in the [101] zone axis according to the orthorhombic crystal structure. The image proves good crystallinity without defects or dislocations. The corresponding SAED pattern of the crystallite in the same orientation [Figure 2(b)] also supports the orthorhombic crystal structure with the tilt system $a^{0} b^{-} b^{-}$in Glazer's notation $^{[20]}$ as it was determined by XRD and ND. Yang et al. ${ }^{[18 b]}$ claimed that the presence of weak satellite reflections indexed as $(0 k l)$ and $(h 0 l)(h$ or $k=$ odd) in electron diffraction patterns of $\mathrm{SrNbO}_{2} \mathrm{~N}$ and $\mathrm{SrTaO}_{2} \mathrm{~N}$ are attributed to symmetry lowering due to the anion ordering. Oró-Solé et al. ${ }^{[15 \mathrm{~b}]}$ observed anion ordering in the perovskite oxynitride $\mathrm{NdVO}_{2} \mathrm{~N}$. Our results did not show weak satellite reflections.

The pre-edge region of the normalized $\mathrm{V} K$-edge XANES spectra of $\mathrm{LaVO}_{2.78} \mathrm{~N}_{0.10}, \mathrm{LaVO}_{3}$, and $\mathrm{LaVO}_{4}$ are shown in Figure 3. XANES is an excellent probe for the oxidation state and chemical environment of the elements and it is highly sensitive to the local structure such as bond angles and bond lengths around the X-ray absorbing element. ${ }^{[21]}$ In this study, an intense pre-edge feature at $5.4696 \mathrm{keV}$ uniquely distinguishes the V $K$-edge XANES spectrum of $\mathrm{LaVO}_{4}$ indicating that vanadium is coordinated tetrahedrally and is in the oxidation state $\mathrm{V}^{5+}{ }^{[22]}$ This pre-edge peak is drastically diminished in the XANES spectrum of $\mathrm{LaVO}_{2.78} \mathrm{~N}_{0.10}$ implying that the local structure around the vanadium ion in $\mathrm{LaVO}_{2.78} \mathrm{~N}_{0.10}$ is entirely different from that of the precursor $\mathrm{LaVO}_{4}$. The preedge feature of $\mathrm{LaVO}_{2.78} \mathrm{~N}_{0.10}$ is, in contrast, almost identical to that of $\mathrm{LaVO}_{3}$ indicating that with the conversion of $\mathrm{LaVO}_{4}$ to $\mathrm{LaVO}_{2.78} \mathrm{~N}_{0.10}$ the coordination environment of the vanadium ion changes from tetrahedral $\left(\mathrm{VO}_{4}\right)$ to octahedral $\left[\mathrm{V}(\mathrm{O}, \mathrm{N})_{6}\right]$. This is consistent with the long range order of the crystal structure evident from XRD, ND, and SAED patterns. Moreover, XANES spectra indirectly reveal that the oxidation state of vanadium changes from $\mathrm{V}^{5+}$ in $\mathrm{LaVO}_{4}$ to $\mathrm{V}^{3+}$ in 

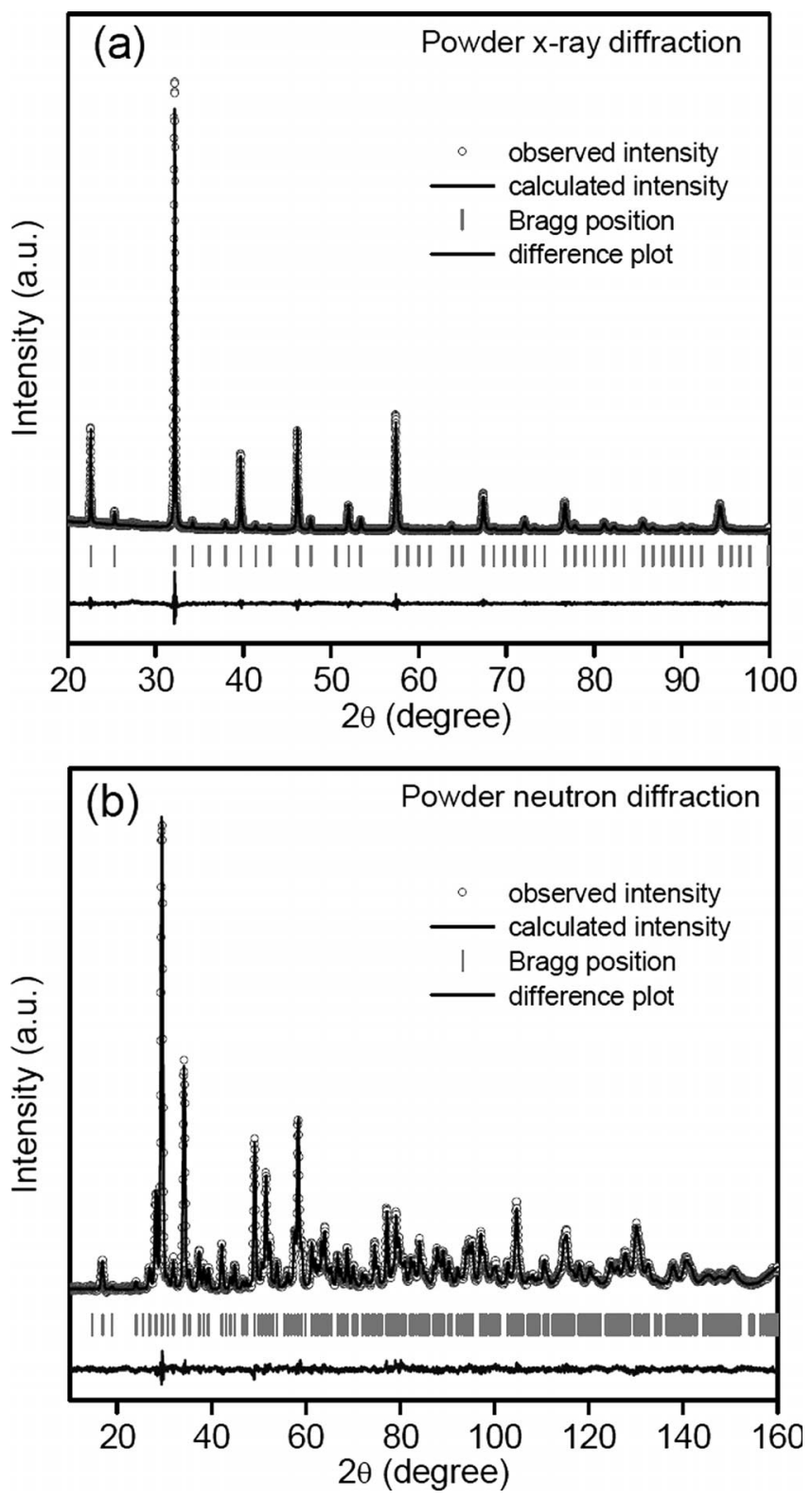

Figure 1. (a) Powder X-ray diffraction pattern (X-ray wavelength: $1.5406 \AA$ ) and Le Bail fitting plot and (b) powder neutron diffraction pattern (neutron wavelength: $1.155 \AA$ ) and Rietveld refinement plot of $\mathrm{LaVO}_{2.78} \mathrm{~N}_{0.10}$ obtained at room temperature. The difference plot of observed and calculated diffraction profiles is shown beneath and the Bragg positions are given by short vertical tick markers.

$\mathrm{LaVO}_{2.78} \mathrm{~N}_{0.10}$. However, we cannot rule out the existence of a small amount of vanadium ions in different oxidation states.

The thermal stability and re-oxidation behavior was investigated by TGA. Figure 4(a) illustrates the weight change upon heating the oxynitride powder in $\mathrm{O}_{2}$. $\mathrm{LaVO}_{2.78} \mathrm{~N}_{0.10}$ is thermally stable up to about $573 \mathrm{~K}$. Above this temperature, the oxygen uptake leads to a mass increase up to about $900 \mathrm{~K}$ followed by a gradual mass loss $(\Delta m \approx 6.17 \%)$ commonly observed in oxynitrides during the re-oxidation process. ${ }^{[23]}$ The re-oxidized powder was identified by XRD as $\mathrm{LaVO}_{4}$. The evolved gases were determined by mass spectrometry [Figure 4(b)]. The MS signal of $\mathrm{N}_{2}(m / z=28)$ indicates the
Table 1. Crystallographic and structural refinement data ${ }^{\text {a) }}$.

\begin{tabular}{lll}
\hline Chemical formular & $\mathrm{LaVO}_{2.78} \mathrm{~N}_{0.10}$ & \\
\hline Radiation & X-ray $\left(\mathrm{Cu}-K_{\alpha 1}\right)$ & $\begin{array}{l}\text { Neutron } \\
\text { orthorhombic } \\
\text { orthorhombic }\end{array}$ \\
Crystal system & $P n m a$ & Pnma \\
Space group & 4 & 4 \\
$Z$ & $5.5526(1)$ & $5.5516(2)$ \\
Lattice parameter $a / \AA$ & $7.8496(1)$ & $7.8469(2)$ \\
Lattice parameter $b / \AA$ & $5.5574(1)$ & $5.5620(2)$ \\
Lattice parameter $c / \AA$ & 242.222 & 242.294 \\
$V / \AA^{3}$ & 4.39 & 2.85 \\
$R_{\mathrm{p}} / \%$ & 5.64 & 3.57 \\
$R_{\text {wp }} / \%$ & 3.78 & 2.67 \\
$R_{\text {exp }} / \%$ & 2.23 & 1.78 \\
$\chi^{2}$ & 1.5406 & 1.155 \\
Wavelength $/ \AA$ & $20-100$ & $3.95-164.90$ \\
$2 \theta$ range $/{ }^{\circ}$ & 0.0167 & 0.05 \\
$2 \theta$ step width $/{ }^{\circ}$ &
\end{tabular}

a) Numbers in parentheses are standard deviations; $R_{\mathrm{p}}, R_{\mathrm{wp}}, R_{\mathrm{exp}}$, and $\chi^{2}$ are the reliability factors and goodness-of-fit, respectively.

release of $\mathrm{N}_{2}$ in the temperature range of $473 \mathrm{~K}<T<900 \mathrm{~K}$. The gradual mass decrease above $900 \mathrm{~K}$ is also accompanied by a small hump in the MS signal at $1273 \mathrm{~K}$, which is caused by the complete release of the remaining $\mathrm{N}_{2}$.

The temperature dependence of the electrical conductivity in the temperature range of $119-302 \mathrm{~K}$ is presented in Figure 5(a). From the Arrhenius plot shown in Figure 5(b) the following relationship can be deduced:

$\sigma=\sigma_{0} \exp \left(-E_{\mathrm{a}} / k_{\mathrm{B}} T\right)$

where $E_{\mathrm{a}}$ is the activation energy of electrical conduction, $k_{\mathrm{B}}$ the Boltzmann constant, $T$ the absolute temperature, and $\sigma_{0}$ the pre-exponential factor. By means of the best-fit line an activation energy of conduction $\left(E_{\mathrm{a}}\right)$ was determined to be $0.103 \mathrm{eV}$. This is in good agreement to the activation energy of $0.11 \mathrm{eV}$, which was reported for $\mathrm{LaVO}_{2.91} \mathrm{~N}_{0.09 \cdot}{ }^{[15]}$

Figure 6(a) shows the temperature dependence of the Seebeck coefficient $(S)$ in the temperature range of 100-302 K. A positive Seebeck coefficient indicates holes are the dominant charge carriers. Down to $166 \mathrm{~K}, \mathrm{~S}$ slightly decreases with decreasing temperature followed by an increase to a maximum at $138 \mathrm{~K}$. In previous publications, the Néel temperature $\left(T_{\mathrm{N}}\right)$ of $\mathrm{LaVO}_{3}$, below which antiferromagnetic ordering occurs, was reported to be $137 \mathrm{~K} .{ }^{[24]}$ Likewise, Antoine et al. observed antiferromagnetic ordering in $\mathrm{LaVO}_{3-x} \mathrm{~N}_{x}$ at $140 \mathrm{~K},{ }^{[15]}$ which is very close to the temperature of the maximum Seebeck coefficient of $\mathrm{LaVO}_{2.78} \mathrm{~N}_{0.10}$ in this study. Figure 6(b) shows the temperature dependence of the thermal conductivity $(\kappa)$. A very low thermal conductivity was observed over the whole measurement range, which can be attributed to the low density of the pellet. $\kappa$ gradually decreases with decreasing temperature showing an anomalous peak at $138 \mathrm{~K}$. From here $\kappa$ remains almost constant down to $62 \mathrm{~K}$, again gradually decreasing at lower temperatures. However, the origin of the transition at $62 \mathrm{~K}$ is not yet understood.

The magnetic structural change was further investigated by measuring the magnetic susceptibility $(\chi)$. Figure 7 (a) shows that $\chi$ increases with decreasing temperature. The maximum susceptibility appears at $138 \mathrm{~K}$, which Nguyen and 
Table 2. Crystal structural parameters of $\mathrm{LaVO}_{2.78} \mathrm{~N}_{0.10}$ determined by the Rietveld refinement of the powder neutron diffraction pattern.

\begin{tabular}{llllll}
\hline Atom & $x$ & $y$ & $z$ & $B_{\text {iso }} / \AA^{2}$ & Occ. \\
\hline La & $0.0286(2)$ & $1 / 4$ & $0.4937(4)$ & $0.374(17)$ & 0.5 \\
V & 0 & 0 & 0 & 0.4 a) & 0.5 \\
O1/N1 & $0.4909(4)$ & $1 / 4$ & $0.5706(5)$ & $0.447(2)$ & $0.468 / 0.032^{\mathrm{b})}$ \\
O2/N2 & $0.2818(3)$ & $0.0369(2)$ & $0.2186(3)$ & $0.648(2)$ & $0.972 / 0.018^{\mathrm{c})}$ \\
\hline
\end{tabular}

a) Isotropic thermal factor $\left(B_{\text {iso }}\right)$ for $\mathrm{V}$ is fixed during the refinement otherwise the refinement have not converged. b) Linear constrain: $\mathrm{O} 1+$ $\mathrm{N} 1=0.5$. c) Linear constrain: $\mathrm{O} 2+\mathrm{N} 2=1.0$.
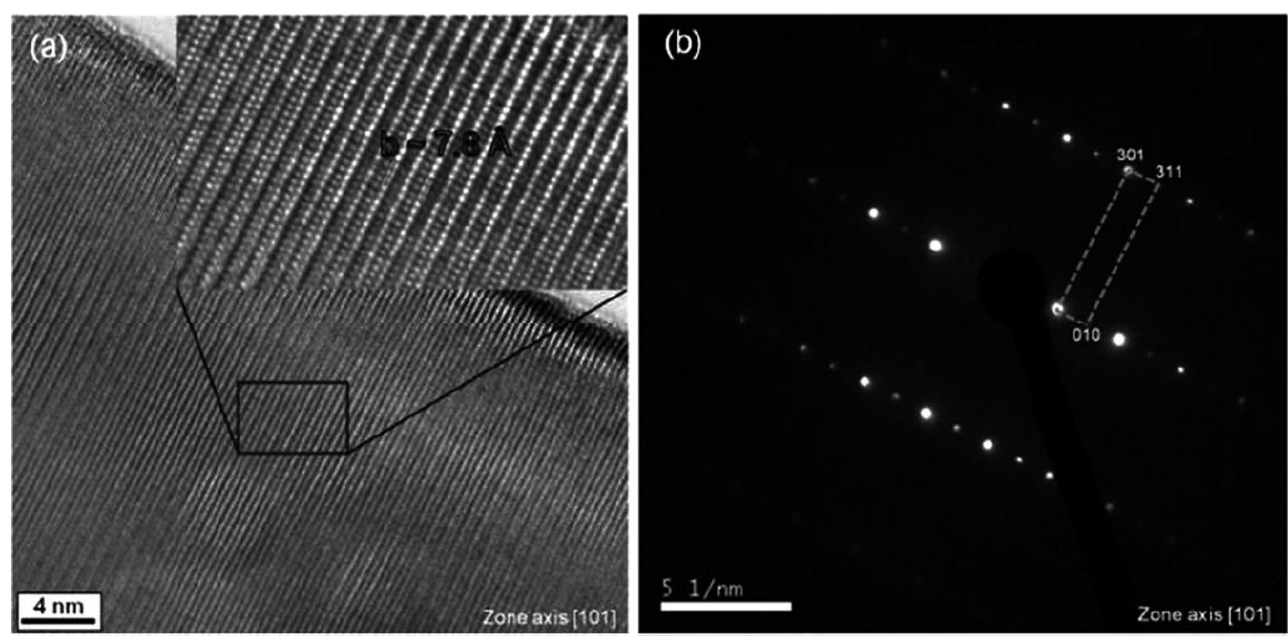

Figure 2. (a) HR-TEM image and (b) electron diffraction pattern of $\mathrm{LaVO}_{2.78} \mathrm{~N}_{0.10}$.

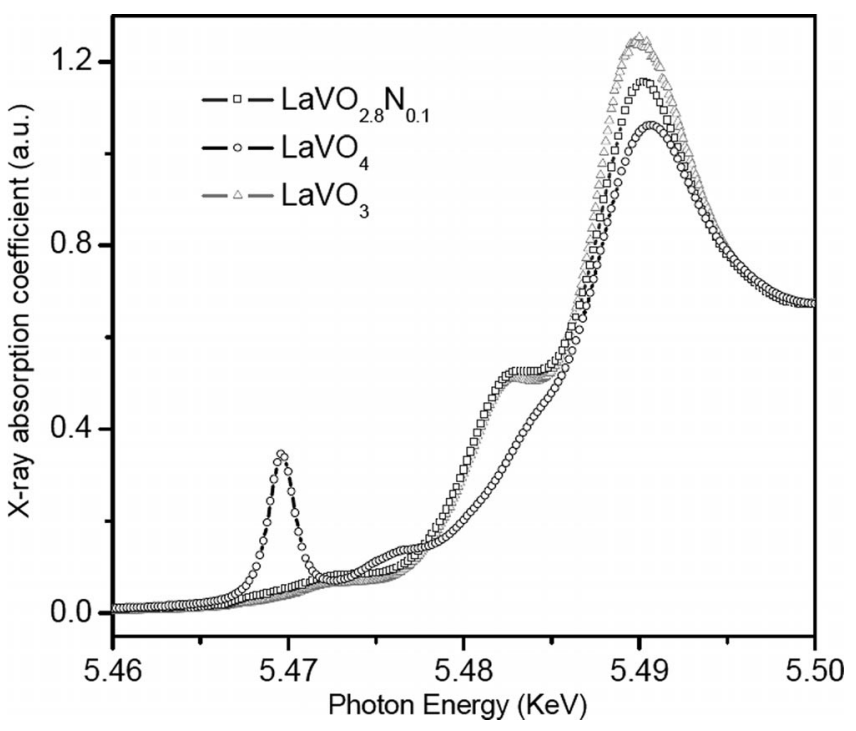

Figure 3. XANES spectra at the $\mathrm{V} K$-edge of $\mathrm{LaVO}_{2.78} \mathrm{~N}_{0.10}, \mathrm{LaVO}_{4}$, and $\mathrm{LaVO}_{3}$.

Goodenough have explained with the presence of a canted-spin ferromagnetism as a result of the Dzialoshinskii antisymmetric exchange in $\mathrm{LaVO}_{3}{ }^{[19 \mathrm{a}]}$ and is also in good agreement with the Seebeck coefficient measurement. After a drastic decrease in the range of $138 \mathrm{~K}$ to $84 \mathrm{~K}$, the susceptibility increases again with decreasing temperature. The second transition temperature $(84 \mathrm{~K})$ was found to be slightly increased compared to the transition temperature $(62 \mathrm{~K})$ obtained from thermal conductivity measurements. At present, it is difficult to conclude what can be the origin of increased magnetic susceptibility below $84 \mathrm{~K}$. It might be related to the existence of a small amount of paramagnetic secondary phases formed during the thermal ammonolysis or to the presence of intrinsic electronic point defects with varying vanadium oxidation states. Above the Néel temperature, the susceptibility is inversely proportional to the temperature [Figure 7(b)], correspondent to the CurieWeiss law

$\chi=\frac{C}{T-\theta}$

where $\chi$ is the susceptibility, $C$ the Curie constant, $T$ the absolute temperature, and $\theta$ the Weiss constant. $C=$ $1320.76 \mathrm{~kg} \mathrm{~K} \mathrm{~m}^{-3}$ and $\theta=-1018.2 \mathrm{~K}$ were obtained by fitting in the temperature range of 160 to $300 \mathrm{~K}$. The Weiss constant $\theta=-670 \mathrm{~K}$ was reported for $\mathrm{LaVO}_{3},{ }^{[19 \mathrm{a}]}$ which is smaller than that of $\mathrm{LaVO}_{2.78} \mathrm{~N}_{0.10}$ in this study. The temperature-dependent Figure of merit

$\mathrm{ZT}=\frac{S^{2} \sigma}{\kappa} T$

is a measure of the quality of a thermoelectric material. ${ }^{[25]}$ The maximum $\mathrm{ZT}$ value of $\mathrm{LaVO}_{2.78} \mathrm{~N}_{0.10}$ was calculated to be $7.27 \times 10^{-6}$ at $302 \mathrm{~K}$. This ZT is too low for efficient thermoelectric applications but it might be increased by cation substitutions and/or advanced sintering techniques such as spark plasma sintering (SPS) to enhance grain boundary connectivity.

Figure 8(a) shows the normalized $\mathrm{X}$-band Electron paramagnetic resonance (EPR) spectra of $\mathrm{LaVO}_{2.78} \mathrm{~N}_{0.10}$ as a function of temperature between $5 \mathrm{~K}$ and $297 \mathrm{~K}$. A signal with $g=$ 

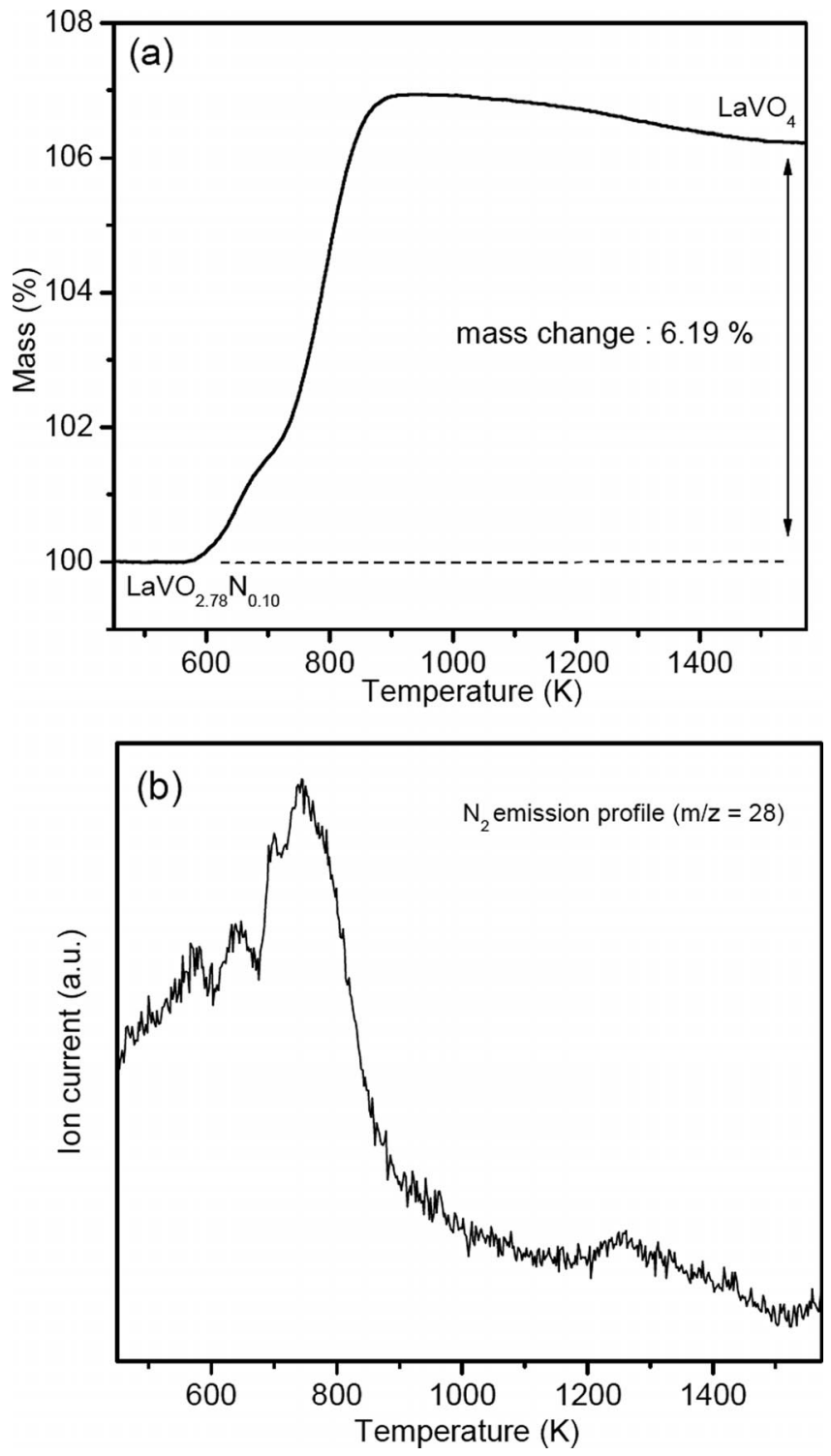

Figure 4. (a) Thermogravimetric analysis (TGA) and (b) mass spectrometry (MS) carried out during the thermal reoxidation of $\mathrm{LaVO}_{2.78} \mathrm{~N}_{0.10}$.

2.00 (1) can be observed at $297 \mathrm{~K}$ with $\Delta \mathrm{B}_{\mathrm{pp}}=27 \mathrm{mT}$. This signal might be attributed to a defect signal like a singly charged oxygen vacancy $\left(\mathrm{V}_{\mathrm{O}}^{*}\right)$, but it may as well be the superposition of well-resolved EPR spectrum ending up with the broad signal. Upon cooling down to $5 \mathrm{~K}$ the $g$-value is changing from $g=2.00(1)$ to $g=1.94(1)$. At $5 \mathrm{~K}$ a half-field signal was still observed and only for spin systems with $S>1 / 2$ can be the origin of it. Therefore, the observed EPR signal can be attributed to $\mathrm{V}^{3+}$ with $S=1$, while $\mathrm{V}^{4+}$ with $S=1 / 2$ can be ruled out. The lineshape of the EPR signal at $g=1.94$ was fitted by a Lorentzian function. The linewidth at $5 \mathrm{~K}$ is reduced to $17 \mathrm{mT}$ compared to $26 \mathrm{mT}$ at room temperature. The narrowing of the signal and the Lorentzian lineshape can be attributed to an exchange coupled system. Temperature dependence of the inverse susceptibility and the $g$-value of $\mathrm{LaVO}_{2.78} \mathrm{~N}_{0.10}$ are shown in Figure 8(b). From room temperature to $150 \mathrm{~K}$ the
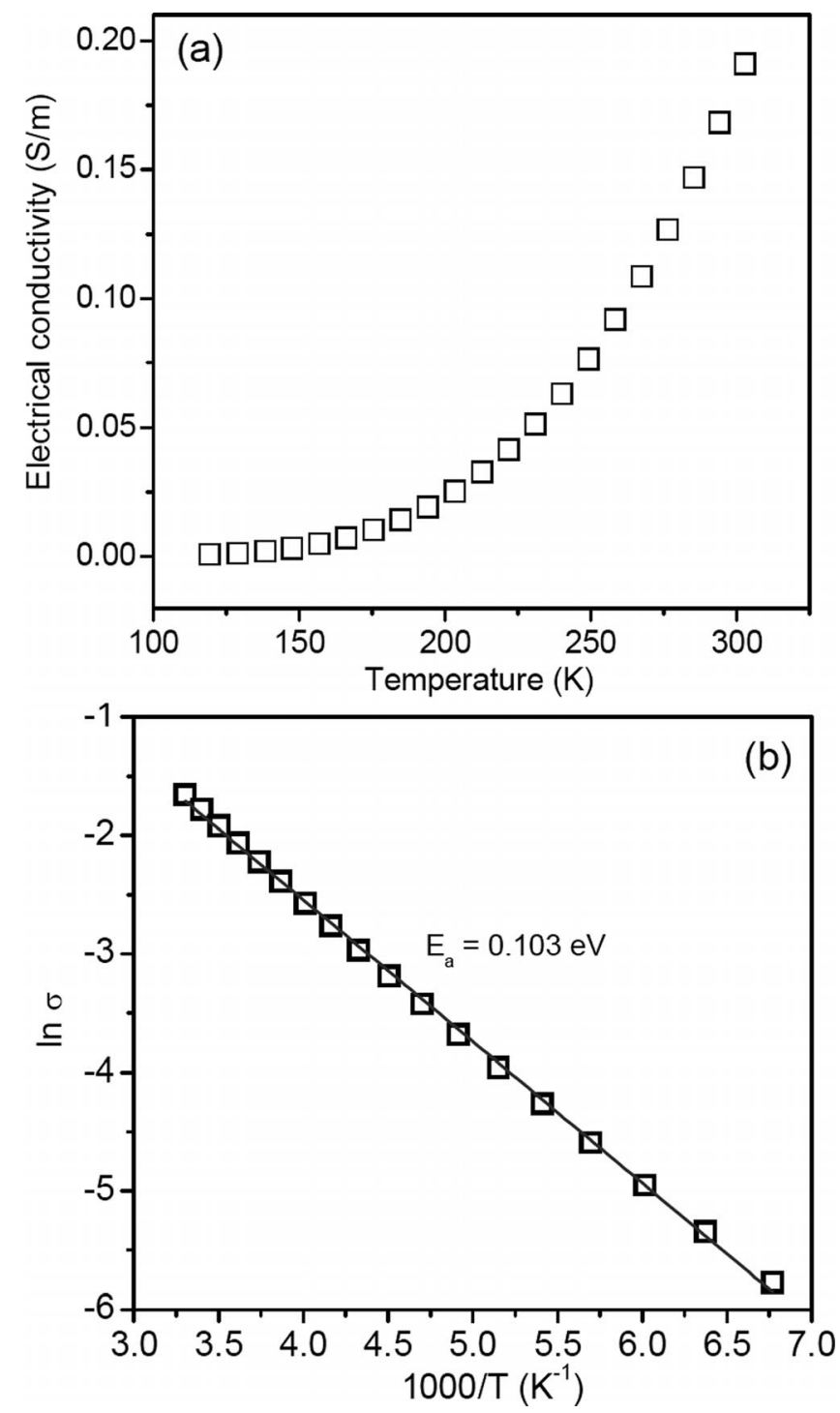

Figure 5. (a) Temperature dependence of the electrical conductivity of $\mathrm{LaVO}_{2.78} \mathrm{~N}_{0.10}$ and (b) Arrhenius plot of $\ln \sigma$ vs. $T^{-1}$.

reciprocal susceptibility is linearly decreasing. Extrapolation of the fit gives a Néel temperature of $137 \mathrm{~K}$, which is in good agreement with the values from the Seebeck coefficient $(S)$ and the magnetic susceptibility $(\chi)$ measurements. In the region between $150 \mathrm{~K}$ and $90 \mathrm{~K}$, a plateau is observed where a significant change occurred in the Seebeck coefficient measurement. Below $90 \mathrm{~K}$ down to $5 \mathrm{~K}$ a non-expected paramagnetic behavior was observed. The $g$-value decreases from room temperature down to $110 \mathrm{~K}$ and the $g$-value remains constant from $110 \mathrm{~K}$ down to $5 \mathrm{~K}$.

Normally electrical conduction in a transition metal oxynitride involves a complicated conduction mechanism due to the presence of narrow $3 \mathrm{~d}$ bands. The electrical conduction may either originate from thermally activated band transition and/ or variable range hopping process. ${ }^{[26]}$ From the Arrhenius plot of the electrical conductivity [Figure 5(b)], it is clearly seen that the conduction process is thermally activated band transition in the temperature range of $119-302 \mathrm{~K}$. This result indi- 

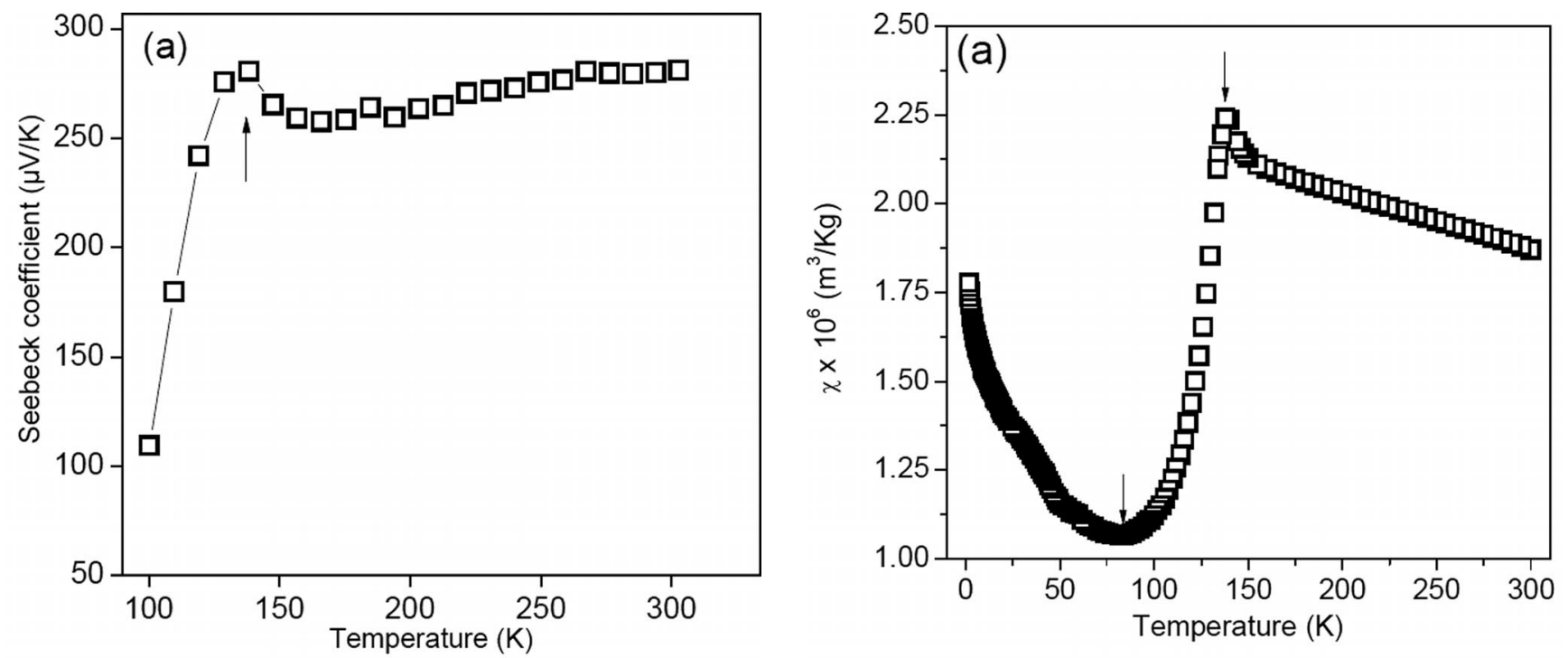

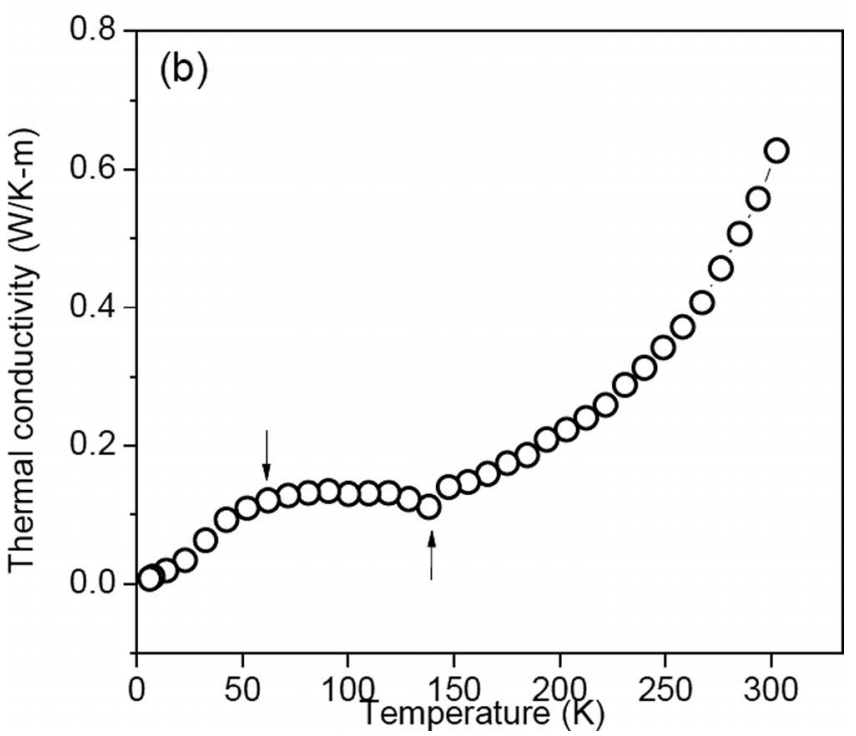

Figure 6. Temperature dependence of (a) Seebeck coefficient and (b) thermal conductivity of $\mathrm{LaVO}_{2.78} \mathrm{~N}_{0.10}$. Arrows indicate the anomalous transition points.

cates that the conduction mechanism of $\mathrm{LaVO}_{2.78} \mathrm{~N}_{0.10}$ is not entirely different from that of $\mathrm{LaVO}_{3}{ }^{[24 \mathrm{~b}, 27]}$ and is also in good agreement with the previous report in $\mathrm{LaVO}_{3-x} \mathrm{~N}_{x}{ }^{[15]}$

\section{Conclusions}

Perovskite-type oxynitride $\mathrm{LaVO}_{2.78} \mathrm{~N}_{0.10}$ was synthesized by thermal ammonolysis of $\mathrm{LaVO}_{4}$. The crystal structure, electrical transport, and magnetic properties were investigated. $\mathrm{X}$-ray, neutron, and electron diffraction studies reveal an orthorhombic crystal structure with Pnma space group. $\mathrm{LaVO}_{2.78} \mathrm{~N}_{0.10}$ shows an Arrhenius-type electrical conductivity with activation energy of $0.103 \mathrm{eV}$. Investigations of the temperature dependence of the Seebeck coefficient, the thermal conductivity, and the magnetic susceptibility reveal an anomaly at $138 \mathrm{~K}$ due to the antiferromagnetic ordering.

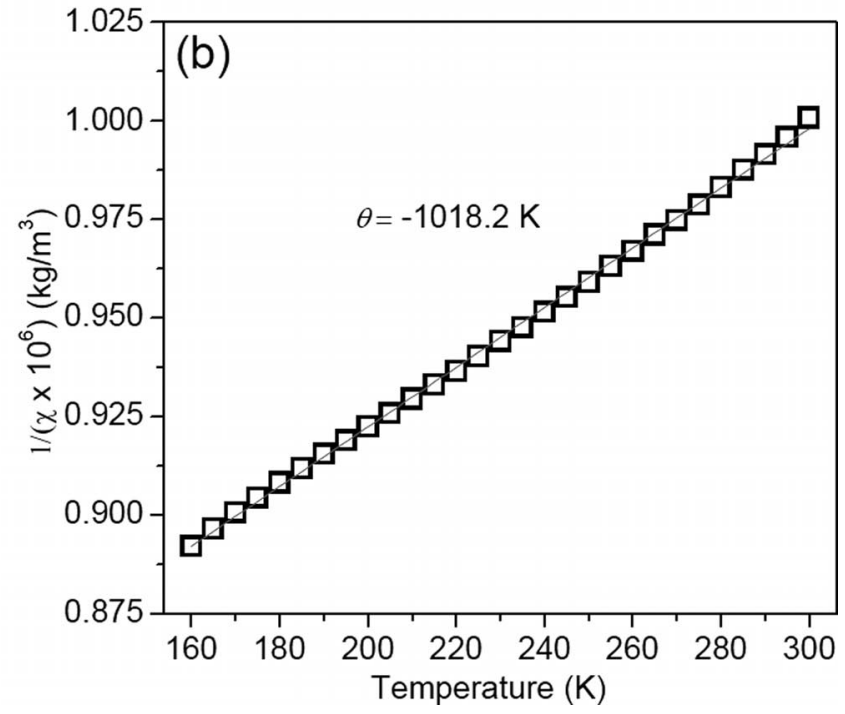

Figure 7. (a) Mass magnetic susceptibility $(\chi)$ of $\mathrm{LaVO}_{2.78} \mathrm{~N}_{0.10}$ in the temperature range of 1.8 to $300 \mathrm{~K}$ and (b) inverse susceptibility $\left(\chi^{-1}\right)$ plot in the temperature range of 160 to $300 \mathrm{~K}$.

\section{Experimental Section}

Lanthanum vanadium oxynitride powder was synthesized via thermal ammonolysis of $\mathrm{LaVO}_{4}$ prepared by solid-state reaction. Stoichiometric amounts of $\mathrm{La}_{2} \mathrm{O}_{3}$ (Alfa Aesar, 99.99\%) and $\mathrm{V}_{2} \mathrm{O}_{5}$ (Alfa Aesar, $99.6 \%$ ) were thoroughly ground using an agate mortar. The mixture was calcined in air at $1273 \mathrm{~K}$ for $12 \mathrm{~h}$ and at $1473 \mathrm{~K}$ for $12 \mathrm{~h}$ with intermediate grinding. Phase purity of the $\mathrm{LaVO}_{4}$ powder was confirmed with powder X-ray diffraction (XRD) (not shown here). The ammonolysis reaction was performed in a rotating cavity reactor. $\mathrm{LaVO}_{4}$ (about $3 \mathrm{~g}$ ) was heated at $1123 \mathrm{~K}$ for $6 \mathrm{~h}$ in a $\mathrm{NH}_{3}$ flow (Messer, $\geq 99.99 \%$ ) of $100 \mathrm{~mL} \cdot \mathrm{min}^{-1}$. Subsequently, the oxynitride samples were quenched to room temperature under flowing $\mathrm{NH}_{3}$.

Oxygen and nitrogen content of the ammonolyzed powder was determined by hot-gas extraction using a Horiba EMGA 820 analyzer. About $10 \mathrm{mg}$ of sample together with a Ni-flux was placed in a graphite crucible and rapidly heated up to $3000{ }^{\circ} \mathrm{C}$ using an electrode impulse furnace. The oxygen generated during the sample decomposition 

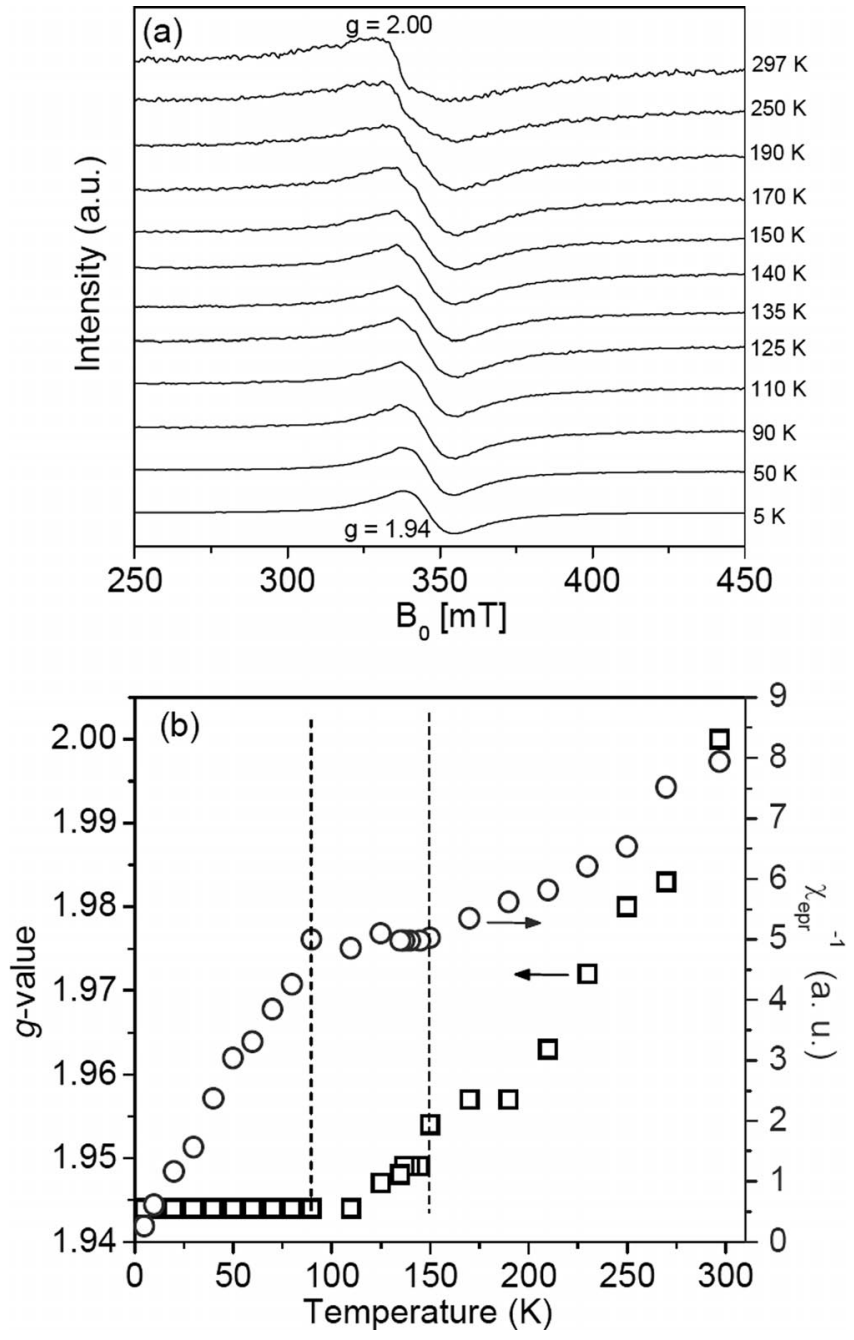

Figure 8. (a) Normalized X-band EPR spectra of $\mathrm{LaVO}_{2.78} \mathrm{~N}_{0.10}$ in the temperature range of 5 to $297 \mathrm{~K}$ and (b) temperature dependence of the $g$-value and inverse susceptibility $\left(\chi^{-1}\right)$.

reacted with the graphite crucible forming $\mathrm{CO}$ and finally $\mathrm{CO}_{2}$, which was detected quantitatively using an infrared detector. The evolved nitrogen was detected in its molecular form with a thermal conductivity detector. $\mathrm{Y}_{2} \mathrm{O}_{3}$ and $\mathrm{Si}_{3} \mathrm{~N}_{4}$ were used as calibration standards for oxygen and nitrogen, respectively. The measurements were repeated three times and the obtained oxygen and nitrogen amounts were averaged.

Powder XRD patterns were obtained with a PANalytical X'Pert PRO $\theta-2 \theta$ scan system equipped with a Johansson monochromator $\left(\mathrm{Cu}-K_{\alpha 1}\right.$ radiation, $1.5406 \AA$ ) and an $\mathrm{X}^{\prime}$ Celerator linear detector. The diffraction patterns were recorded from $20^{\circ}$ to $100^{\circ}$ in $2 \theta$ with an angular step interval of $0.0167^{\circ}$. XRD pattern of the oxynitride was analyzed by the Le Bail method ${ }^{[28]}$ incorporated in the Rietveld refinement program, FullProf ${ }^{[29]}$ to determine the space group and lattice parameters. The Thompson-Cox-Hastings pseudo-Voigt function ${ }^{[30]}$ was chosen as profile function and the background was modeled with a sixth-order polynomial function. The instrumental contribution for peak broadening was estimated with the measurement of the standard reference sample $\mathrm{CeO}_{2}$ (NIST SRM674b).

Powder neutron diffraction (ND) pattern was collected with the highresolution powder diffractometer for thermal neutrons (HRPT) located at the Swiss Spallation Neutron Source at the Paul Scherrer Institute (Villigen, Switzerland). The powder sample was placed in a vanadium cylinder. The measurement was carried out with a neutron wavelength of $1.155 \AA$ from $3.95^{\circ}$ to $164.90^{\circ}$ in $2 \theta$ with a step size of $0.05^{\circ}$. Rietveld refinement was carried out with the FullProf suite.

Selected area electron diffraction (SAED) and high-resolution transmission electron microscopy (HR-TEM) studies were performed with a JEOL JEM-2200FS electron microscope operating at $200 \mathrm{kV}$. A TEM sample was prepared by dispersion of the oxynitride powder in ethanol and deposition on a grid covered with a carbon layer.

V $K$-edge X-ray absorption spectra (XAS) were measured using synchrotron radiation at the beamline A1 of the HASYLAB (Hamburger Synchrotronstrahlungslabor) at DESY (Deutsches Elektronen-Synchrotron, Hamburg, Germany). The incident X-ray beam energy was adjusted using a $\mathrm{Si}(111)$ double crystal monochromator. Higher order harmonics were suppressed by detuning the second monochromator crystal to $50 \%$ of the maximum energy. The samples were mixed with polyethylene and pressed into pellets of $13 \mathrm{~mm}$ diameter. The spectra were collected in transmission mode at room temperature and processed using the program WinXAS. ${ }^{[31]}$ The background was corrected in the energy range of $5.3500-5.4450 \mathrm{keV}$ by substraction of a linear function. Subsequently, the XAS spectrum was normalized in the energy range of 5.4880-5.4960 keV. The photon energy was calibrated to the first inflection point in the spectrum of a vanadium metal foil and assigned to $5.4658 \mathrm{keV}$.

The thermal re-oxidation study by thermogravimetric analysis (TGA) was carried out with a NETZSCH STA 409 CD thermobalance. Oxynitride powder (about $120 \mathrm{mg}$ ) was heated in an alumina crucible in $\mathrm{O}_{2}$ $\left(50 \mathrm{~mL} \cdot \mathrm{min}^{-1}\right)$ to $1573 \mathrm{~K}$ at a heating rate of $10 \mathrm{~K} \cdot \mathrm{min}^{-1}$. Gas analysis was done with a connected mass spectrometer (MS).

Physical properties measurements were performed in the temperature range of 6-302 K with a PPMS (Quantum Design, Inc.). Transport properties were measured on a bar $(10 \mathrm{~mm} \times 3 \mathrm{~mm} \times 2 \mathrm{~mm})$ obtained by applying a uniaxial pressure of 20 bar on oxynitride powder followed by cold isostatic pressing at 2000 bar.

Magnetic susceptibility measurement was carried out with a superconducting quantum interference device (SQUID) magnetometer (SHE905). The field strength was 500 Oe $\left[5 \times 10^{5} / 4 \pi(\mathrm{A} / \mathrm{m})\right]$ and the data was collected upon cooling in the temperature range of $2-300 \mathrm{~K}$.

Electron paramagnetic resonance (EPR) experiments were performed at X-Band $(9.5 \mathrm{GHz})$ frequency with a BRUKER EMX spectrometer with a rectangular resonator. The magnetic field was calibrated with a standard field marker (DPPH) with $g=2.0036$. A helium-flow cryostat (Oxford Instruments) was used for low temperature measurements. The spin-concentration was determined by numerical double integration of the continuous-wave (c.w.) EPR spectrum.

\section{Acknowledgements}

The authors are grateful to Dr. Karl Krämer at the University of Bern for his support with the SQUID measurement. The neutron experiments were performed at the Swiss Spallation Neutron Source, SINQ, at the Paul Scherrer Institute, Villigen, Switzerland (proposal-number 20110416). The authors thank Dr. Denis Sheptyakov for the helpful discussion and support during the neutron measurement campaign. Part of this research was carried out at the synchrotron DORIS III at DESY, a member of the Helmholtz Association (HGF). We would like to thank Dr. Edmund Welter for his assistance. 


\section{References}

[1] H. D. Megaw, Nature 1945, 155, 484-485.

[2] F. Galasso, Perovskites and High-Tc Superconductors, Gordon and Breach, New York 1990.

[3] A. P. Ramirez, J. Phys. Condens. Matter 1997, 9, 8171-8199.

[4] a) G. H. Haertling, J. Am. Ceram. Soc. 1999, 82, 797-818; b) D. Damjanovic, Rep. Prog. Phys. 1998, 61, 1267-1324; c) R. Ramesh, N. A. Spaldin, Nat. Mater. 2007, 6, 21-29.

[5] A. Weidenkaff, R. Robert, M. Aguirre, L. Bocher, T. Lippert, S. Canulescu, Renew. Energ. 2008, 33, 342-347.

[6] P. Egger, J. Hulliger, Coord. Chem. Rev. 1999, 183, 101-115.

[7] a) A. Kasahara, K. Nukumizu, G. Hitoki, T. Takata, J. N. Kondo, M. Hara, H. Kobayashi, K. Domen, J. Phys. Chem. A 2002, 106, 6750-6753; b) C. Le Paven-Thivet, A. Ishikawa, A. Ziani, L. Le Gendre, M. Yoshida, J. Kubota, F. Tessier, K. Domen, J. Phys. Chem. C 2009, 113, 6156-6162.

[8] R. H. Mitchell, Perovskites: Modern and Ancient, Almaz Press, Thunder Bay, Canada, 2002.

[9] a) A. Fuertes, Dalton Trans. 2010, 39, 5942-5948; b) M. Jansen, H. P. Letschert, Nature 2000, 404, 980-982; c) S. G. Ebbinghaus, H. P. Abicht, R. Dronskowski, T. Muller, A. Reller, A. Weidenkaff, Prog. Solid State Chem. 2009, 37, 173-205; d) Y. I. Kim, P. M. Woodward, J. Solid State Chem. 2007, 180, 3224-3233; e) R. Marchand, Y. Laurent, J. Guyader, P. Lharidon, P. Verdier, J. Eur. Ceram. Soc. 1991, 8, 197-213.

[10] Y. I. Kim, P. M. Woodward, K. Z. Baba-Kishi, C. W. Tai, Chem. Mater. 2004, 16, 1267-1276.

[11] a) K. Maeda, M. Higashi, B. Siritanaratkul, R. Abe, K. Domen, J. Am. Chem. Soc. 2011, 133, 12334-12337; b) B. Siritanaratkul, K. Maeda, T. Hisatomi, K. Domen, ChemSusChem 2011, 4, 7478.

[12] a) M. Yang, J. Oro-Sole, A. Kusmartseva, A. Fuertes, J. P. Attfield, J. Am. Chem. Soc. 2010, 132, 4822-4829; b) A. B. Jorge, J. Oro-Sole, A. M. Bea, N. Mufti, T. T. M. Palstra, J. A. Rodgers, J. P. Attfield, A. Fuertes, J. Am. Chem. Soc. 2008, 130, 1257212573.

[13] a) G. Liu, X. H. Zhao, H. A. Eick, J. Alloys Compd. 1992, 187, 145-156; b) D. Logvinovich, R. Aguiar, R. Robert, M. Trottmann, S. G. Ebbinghaus, A. Reller, A. Weidenkaff, J. Solid State Chem. 2007, 180, 2649-2654; c) D. Logvinovich, J. Hejtmanek, K. Knizek, M. Marysko, N. Homazava, P. Tomes, R. Aguiar, S. G. Ebbinghaus, A. Reller, A. Weidenkaff, J. Appl. Phys. 2009, 105, 023522 .

[14] a) P. Antoine, R. Marchand, Y. Laurent, C. Michel, B. Raveau, Mater. Res. Bull. 1988, 23, 953-957; b) P. Bacher, P. Antoine, R. Marchand, P. Lharidon, Y. Laurent, G. Roult, J. Solid State Chem. 1988, 77, 67-71.

[15] a) P. Antoine, R. Assabaa, P. Lharidon, R. Marchand, Y. Laurent, C. Michel, B. Raveau, Mater. Sci. Eng. B 1989, 5, 43-46; b) J.
Oró-Solé, L. Clark, W. Bonin, J. P. Attfield, A. Fuertes, Chem. Commun. 2013, 4, 2430-2432.

[16] a) E. B. Maxted, Ammonia and the Nitrides, J. \& A. Churchill, London, 1921; b) A. H. White, W. M. Melville, J. Am. Chem. Soc. 1905, 27, 373-386.

[17] A. Hellwig, A. Hendry, J. Mater. Sci. 1994, 29, 4686-4693.

[18] a) S. G. Ebbinghaus, A. Weidenkaff, A. Rachel, A. Reller, Acta Crystallogr., Sect. C 2004, 60, I91-I93; b) M. H. Yang, J. OroSole, J. A. Rodgers, A. B. Jorge, A. Fuertes, J. P. Attfield, Nat. Chem. 2011, 3, 47-52.

[19] a) H. C. Nguyen, J. B. Goodenough, Phys. Rev. B 1995, 52, 324 334; b) P. Dougier, P. Hagenmul, J. Solid State Chem. 1974, 11, 177-183; c) N. H. Hur, S. H. Kim, K. S. Yu, Y. K. Park, J. C. Park, S. J. Kim, Solid State Commun. 1994, 92, 541-546; d) R. T. A. Khan, J. Bashir, N. Iqbal, M. N. Khan, Mater. Lett. 2004, $58,1737-1740$.

[20] M. Glazer, Acta Crystallogr., Sect. B 1972, 28, 3384-3392.

[21] a) H. Modrow, Appl. Spectrosc. Rev. 2004, 39, 183-290; b) B. Ravel, E. A. Stern, Physica B 1995, 208, 316-318.

[22] a) P. Frank, K. O. Hodgson, K. Kustin, W. E. Robinson, J. Biol. Chem. 1998, 273, 24498-24503; b) J. M. Arber, E. Deboer, C. D. Garner, S. S. Hasnain, R. Wever, Biochemistry 1989, 28, 79687973.

[23] a) A. Rachel, S. G. Ebbinghaus, M. Gungerich, P. J. Klar, J. Hanss, A. Weidenkaff, A. Reller, Thermochim. Acta 2005, 438, 134-143; b) A. Maegli, S. Yoon, E. Otal, L. Karvonen, P. Mandaliev, A. Weidenkaff, J. Solid State Chem. 2011, 184, 929-936.

[24] a) D. B. Rogers, A. Ferretti, D. H. Ridgley, R. J. Arnott, J. B. Goodenough, J. Appl. Phys. 1966, 37, 1431; b) T. Palanisamy, J. Gopalakrishnan, M. V. C. Sastri, Z. Anorg. Allg. Chem. 1975, 415, 275-284; c) P. Bordet, C. Chaillout, M. Marezio, Q. Huang, A. Santoro, S. W. Cheong, H. Takagi, C. S. Oglesby, B. Batlogg, J. Solid State Chem. 1993, 106, 253-270.

[25] a) D. M. Rowe, Thermoelectrics Handbook - Macro to Nano, CRC Press, Taylor \& Francis Group, Boca Raton, 2006; b) P. Pichanusakorn, P. Bandaru, Mater. Sci. Eng. R 2010, 67, 19-63.

[26] a) P. A. Cox, Transition Metal Oxides: An Introduction to Their Electronic Structure and Properties, Oxford University Press, United Kingdom, 1992; b) J. B. Goodenough, Prog. Solid State Chem. 1971, 5, 145-399.

[27] M. Sayer, R. Chen, R. Fletcher, A. Mansingh, J. Phys. C 1975, 8, 2059-2071.

[28] A. Lebail, H. Duroy, J. L. Fourquet, Mater. Res. Bull. 1988, 23, 447-452.

[29] J. Rodríguez-Carvajal, Physica B 1993, 192, 55-69.

[30] P. Thompson, D. E. Cox, J. B. Hastings, J. Appl. Crystallogr. 1987, 20, 79-83.

[31] T. Ressler, J. Synchrotron Radiat. 1998, 5, 118-122.

Received: November 19, 2013 Published Online: February 25, 2014 